\title{
Um estudo de Interação a Longo Prazo com Aulas de Matemática usando Robôs
}

\author{
Maria Luíza Telles ${ }^{1}$, Adam Henrique Moreira Pinto ${ }^{2}$, Roseli Aparecida Francelin Romero ${ }^{2}$ \\ ${ }^{1}$ Escola de Engenharia de São Carlos - \\ Universidade de São Paulo (USP) \\ Caixa Postal 15.064 - 91.501-970 - São Calos - SP - Brazil \\ ${ }^{2}$ Instituto de Ciências Matemáticas e de Computação - \\ Universidade de São Paulo (USP) - São Carlos, SP - Brasil \\ ${ }^{3}$ Instituto de Ciências Matemáticas e de Computação - \\ Universidade de São Paulo (USP) - São Carlos, SP - Brasil \\ \{maria.telles, adam.moreira\}@wr.sc.usp.br, rafrancedicmc.usp.br
}

\begin{abstract}
The inclusion of the robotics for academic activities is already well established, with good results around the world. However, is robotics really effective in preschool, especially when children have a lasting interaction with the robot? This paper is focused on develop logical, cognitive and mathematical reasoning of 5 and 6 years-old children with the same robot along one and half year. The objective is to analyze if they learned the content approached, and to understand when and why the student loses the interest in classes. The results shown that, for the long-term interaction, it is necessary to focus on four variables: approached manner, success, novelty and engagement.
\end{abstract}

Resumo. A inclusão da robótica para atividades acadêmicas já está bem estabelecida, com bons resultados em todo o mundo. No entanto, a robótica é realmente eficaz na pré-escola, especialmente quando as crianças têm uma interação duradoura com o robô? Este trabalho é focado no desenvolvimento de raciocínio lógico, cognitivo e matemático em crianças de 5 e 6 anos com o mesmo robô ao longo de um ano e meio. O objetivo é analisar se eles aprenderam o conteúdo abordado, e para entender quando e por que o aluno perde o interesse nas aulas. Os resultados mostraram que, para a interação de longo prazo, é necessário focar em quatro fatores: forma abordada, sucesso, novidade e engajamento.

\section{Introdução}

No Brasil, é comum o uso de robôs como alternativa ou auxílio de ensino em várias escolas. A multidisciplinaridade da robótica permite a exploração de diversos temas, tais como matemática, lógica, resolução de problemas, trabalho em equipe, dentre outros. Estes são alguns dos temas mais relevantes na Robótica Educacional, os quais desenvolvem uma perspectiva de resolução de problemas diários de maneira lógica, criando uma tipo de aprendizagem [Oliveira 2007]. A real efetividade do uso de robôs numa interação a longo prazo é uma das maiores preocupações na robótica educacional, em especial com crianças muito novas. $\mathrm{O}$ fator novidade tem grande peso no aprendizado, visto que 
VIII Congresso Brasileiro de Informática na Educação (CBIE 2019)

Anais do XXX Simpósio Brasileiro de Informática na Educação (SBIE 2019)

mantém a atenção do estudante na aula por mais tempo que o método tradicional. Porém, conforme o robô se torna parte da rotina, esta premissa pode deixar de ser verdadeira.

Este estudo visa comparar o aprendizado de alunos da pré-escola após um ano e meio interagindo com um kit robótico educacional. O estudo, que foi assistido por profissionais da área da educação e psicologia, buscou uma abordagem construcionista para o ensino, permitindo o ensino de assuntos mais complexos para estes alunos, por meio da interação aluno-objeto. Foi utilizado um kit robótico aplicado ao ensino de matemática e sobre conceitos de robótica em si, usando diversos jogos nos quais o tema era apresentado de forma indireta. Os testes são aplicados baseados em dados pedagógicos e psicológicos e comparados aos métodos comuns [Andujar et al. 2011]. Este artigo está organizado da seguinte forma. Na Seção 2, é discutido sobre pesquisas relacionadas. A metodologia adotada na pesquisa é descrita na Seção 3. Na Seção 4, são descritos as atividades e experimentos aplicados, assim como o material utilizado para a execução das atividades. $\mathrm{Na}$ Seção 5, discussões são feitas a partir dos resultados obtidos. Por fim, na Seção 6, são apresentados a conclusão e trabalhos futuros.

\section{Trabalhos Relacionados}

No contexto de aprendizagem significativa idealizado por [Ausubel 1982], Robótica pode ser utilizada para apoiar o processo de construção do conhecimento no ensino e aprendizado de matemática, uma vez que cria especulação sobre esta prática e a melhoria do conhecimento desenvolvido pelo estudante. De acordo com [Vygotsky 1993], o aprendizado pode ser fortalecido por meio da associação de informações abstratas com objetos reais, causando uma melhor memorização. Consequentemente, um método agradável para melhorar os processos de aprendizagem e memorização é a utilização de meio abstrato tal como músicas e símbolos. Portanto, é importante citar o ambiente educacional robótico pelas teorias de Jean Piaget, as quais foram revisadas por Seymour Papert. De acordo com [Chella 2005], é afirmado que este aprendizado fortalece a participação ativa do estudante, o qual pode expandir seu conhecimento ao manipular dados significativos, objetos e símbolos. Robótica, jogos e outras tecnologias educacionais são ferramentas que servem como símbolos para o aumento do aprendizado [Perrenoud 1999].

Em uma visão geral de robôs sociais usados para longa interação, de acordo com [Leite et al. 2013], esta é uma área recente e mostra que pessoas são capazes de aceitar e interagir com robôs por longos períodos, mas ainda há muito trabalho a ser feito. Especificamente, sobre a robótica aplicada em ambiente educacional, os robôs capazes de simular comportamentos sociais complexos e diversos conseguem envolver as crianças a longo prazo. Assim como o ambiente em que o robô está inserido e as atividades que ele realiza cativam os alunos com mais frequência.

Pensando na exclusão digital, realidade em algumas regiões do Brasil, [Thomaz et al. 2009] visa a implementação de um projeto envolvendo computadores e robôs no subúrbio de Natal - RN. Os alunos foram orientados a realizar tarefas que estimulassem o raciocínio lógico, a resolução de problemas e a construção de protótipos de robôs com atividades interdisciplinares. Foi possível perceber o crescimento em média da aprendizagem dos conceitos abordados, por crianças participantes do projeto. Individualmente, os alunos foram comparados com aqueles que não participaram do experimento robótico e observou-se uma melhora de até 2 pontos em média. No entanto, apenas a 
VIII Congresso Brasileiro de Informática na Educação (CBIE 2019)

Anais do XXX Simpósio Brasileiro de Informática na Educação (SBIE 2019)

inserção de tecnologia não significa melhoria de aprendizado e estudo. Um experimento usando capacete neural por [Andujar et al. 2011] mostra que não houve diferença estatisticamente significativa entre pessoas que estudaram através de tablets e pessoas que estudaram usando livros. Por isso, é importante a participação de profissionais especializados na criação das atividades, como neste trabalho, para que o aprendizado possa ser mais efetivo.

\section{Metodologia}

Esta pesquisa foi desenvolvida junto ao Centro de Convivência Infantil (CCI) da USP/São Carlos. Nas primeiras aulas, as crianças aprenderam sobre as partes do robô (parafusos, porcas e peças de montagem). Houve também atividades mais leves, com um tema de entretenimento, para os alunos aprenderem a operar o dispositivo. Após o primeiro contato, que durou 6 meses, os mesmos já conheciam o robô e os primeiros sinais de desatenção foram percebidos. Portanto, tais noções foram novamente testadas durante um ano, questionando se as crianças poderiam se lembrar destes estudos. Tais testes são os descritos nesta pesquisa. Em seguida, tarefas mais complexas foram iniciadas em conjunto com uma natureza educacional ampla, com o uso contínuo do robô.

Usando um kit robótico, seguiu-se com as atividades aplicadas em sala de aula. Estas atividades foram preparadas para inserir o robô em vários jogos educacionais para reforçar o conhecimento deles em matemática básica. As crianças deveriam discutir sobre as ações que o robô deveria praticar, uma vez que os comandos são muito intuitivos, conforme será discutido na seção 3.1, mas o professor foi quem escreveu o código final e o leu para os estudantes. Os alunos foram responsáveis por montar o robô de acordo com as instruções do professor e por observar sua performance em cada atividade. O kit PETe Educacional foi escolhido para estas atividades.

\subsection{Robótica Educacional Kit PETe}

A PETe é uma empresa brasileira que desenvolve kits de robótica com o objetivo de solucionar desafios dentro do ambiente educacional. Recomendada pelo Ministério da Educação pelo seu Projeto de Educação Tecnológica, a PETe foi a empresa cujos seus produtos foram utilizados para esta pesquisa. O kit Pete que foi utilizado é constituído por: um modulo de controle, suportes, parafusos e porcas, chaves de fenda e inglesa, pilhas e carregadores, motores e servomotores, cabo com conexão USB, sensores e rodas. Juntando todo o material, o robô pode ser montado de maneira simples, realizando tarefas fáceis como andar, de maneira mais complexa, realizando tarefas como identificar faixas, sons, luminosidade entre outros.

O robô pode salvar apenas uma programação em sua memória, tendo apenas uma rotina pré-programada. Para programá-lo, é utilizada a plataforma LEGAL. Ela possui comandos específicos que remetem à programação com linguagens de alto nível. Os comandos são escritos exatamente da forma que o robô deve executar, por exemplo, para o robô andar para frente por 2 segundos, basta usar o comando FRENTE $2 \mathrm{~s}$. Além de escrever cada linha do código, é possível clicar em botões que geram os comandos. Há também uma plataforma exclusiva para crianças ainda não alfabetizadas, o LEGAL júnior, com grandes botões que preenchem toda a tela. É importante ressaltar que a todo instante o kit se mostra muito educativo, por exemplo, o código deve começar com "Por Favor" 


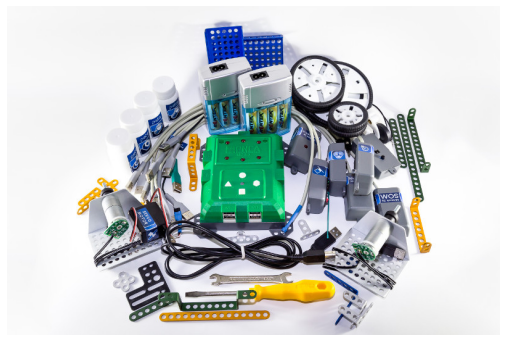

(a) Kit PETe

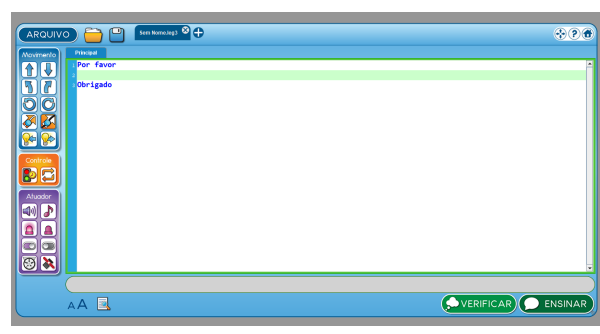

(b) LEGAL Plataform

Figura 1. Kit PETe e a Plataforma LEGAL

e terminar com "Obrigado", ajudando as crianças a entender que devem respeitar o robô. Uma imagem do kit desmontado, bem como um exemplo do ambiente de programação do robô podem ser vistos na Figura 1.

\section{Experimentos}

As aulas foram conduzidas em uma turma de 12 crianças, com idade entre 5 e 6 anos, e pertencentes a pré-escola do CCI. Para facilitar e dar uma maior atenção à atividades das crianças, a turma foi dividida em 3 grupos com 4 alunos cada, onde cada grupo realizou uma sessão de aproximadamente 30 minutos, em um período de um ano. As atividades propostas nas sessões seguem o modelo construtivista de ensino, onde o aluno pode aprender a construir e a comunicar-se com máquinas. Desta forma o robô é usado como um instrumento de aprendizagem e o aluno atua no seu processo de construção de conhecimentos de forma ativa, interagindo com o instrumento de aprendizagem.[Papert 1985].

Como é uma idade complicada para o uso de provas escritas, a avaliação do aprendizado e do engajamento de cada aluno foi realizada através do preenchimento, por parte dos professores, de uma planilha e anotações de falas pertinentes, conforme as intervenções individuais ou em grupo durante a aula. Os experimentos foram divididos em várias aulas, cada um com um tópico matemático ou uma habilidade cognitiva a ser trabalhada e relembrada pelos alunos, as quais serão descritas nas subseções a seguir.

\subsection{Figuras Geométricas}

As figuras geométricas foram um dos conceitos que já haviam sido explorados por outros professores utilizando o mesmo kit robótico, anteriormente a esta pesquisa. Entretanto, com a necessidade de se verificar o que as crianças aprenderam, o presente tema foi recuperado durante algumas aulas. Primeiro foi questionado às crianças, qual era o formato dos botões do robô (mostrado na figura 2), elas responderam corretamente e então, foi feita a próxima atividade. Nesta aula foram utilizadas figuras geométricas feitas de fita preta no chão, com formatos de triângulo, retângulo e quadrado. Os alunos deveriam colocar e ligar o robô no caminho que representasse a figura geométrica pedido pelo professor, e o robô deveria utilizar o sensor de faixa para seguir o percurso indicado. Em todas as atividades, é comum uma certa euforia dos alunos em ver o robô executando a tarefa, mas o aluno só poderia fazer o robô funcionar quando acertasse a figura.

\subsection{Contagem}

O conceito de contagem também foi assunto abordado em trabalhos anteriores por outros professores. Para tal, foram mostrados os sensores para os alunos e explicado que aquelas 


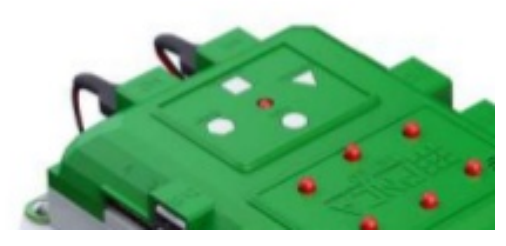

Figura 2. Botões do robô

peças eram como olhos e ouvidos dos robôs. A tarefa deles era contar quantos sensores um robô montado possuía e construir um novo. Assim, eles separaram cada parafuso e cada porca para cada sensor antes de começarem a montagem. As crianças demonstraram facilidade para contar, mas não conseguiam memorizar as quantidades.

\subsection{Distância e velocidade}

Os conceitos de distância e velocidade já foram assuntos abordados anteriormente. Uma foto de uma árvore foi fixada em uma caixa de papelão e o robô tinha que percorrer caminhos que levavam até ela. Na primeira parte da atividade, foi pedido aos alunos que escolhessem o caminho mais curto e depois o mais longo, para verificar o conceito de distância. Depois, para uma aplicação mais indireta, os alunos deveriam escolher o robô que andasse mais rápido. Com essa atividade, foi possível perceber que quando os caminhos não são tão óbvios os alunos apresentaram dificuldade de escolher aquele com menor distância. Já em questão de velocidade, eles demonstraram mais facilidade pois conseguiram diferenciar o que é rápido do que é lento.

\subsection{Lateralidade}

No primeiro contanto com a robótica, as crianças já haviam sido apresentadas ao assunto sobre lateralidade. Entretanto, foi só nestes experimentos que foi formalizado o conceito de "Esquerda/Direita". Para auxiliar no entendimento do conceito, foram montados diversos percursos para que, com o auxílio do robô com sensor de seguir faixa, as crianças respondessem qual dos lados o robô iria percorrer. A mesma atividade foi realizada em três aulas para melhor fixação das crianças e também para a obtenção de mais dados. A principal dificuldade notada foi que elas não conseguiam assimilar que ao considerar um determinado referencial, existe uma direita e esquerda associada a aquele lugar. Por fim, foi notado que com o decorrer das aulas, houve uma melhora na percepção sobre o tema. Apesar da melhora, ainda era necessário exercitar muitas vezes o conceito para que ficasse claro e intuitivo.

\subsection{Aulas de montagem}

Depois de um mês de férias, as aulas de robótica retornaram, permitindo avaliar, pelos experimentos descritos daqui por diante, se as crianças ainda estariam interessadas nas atividades. Nas duas primeiras aulas, foram trabalhados outros tipos de montagens do robô. Foi indicado que as crianças criassem outras formas aos robôs, utilizando os mesmos instrumentos e ferramentas que já tinham conhecimento. Ao decorrer das aulas, as crianças começaram a demonstrar tédio em apertar parafusos e porcas, um trabalho manual que anteriormente elas gostavam de fazer. 
VIII Congresso Brasileiro de Informática na Educação (CBIE 2019)

Anais do XXX Simpósio Brasileiro de Informática na Educação (SBIE 2019)

\subsection{Lateralidade e orientações}

$\mathrm{O}$ assunto foi retomado para verificar se as crianças de fato tinham aprendido quais eram os lados direito e esquerdo, sendo elas o próprio referencial, e quando o referencial era mudado. Primeiramente, as crianças foram instruídas que o robô deveria seguir um caminho específico e, para isso, elas deveriam pedir a ele que virasse à esquerda ou à direita dele próprio, antes de ele iniciar o seu percurso. Assim, as crianças espalhadas pela sala enxergavam o robô em diferentes locais, possibilitando que o referencial do robô não fosse necessariamente o mesmo que o referencial delas. Depois, foi explicado pela primeira vez as posições do plano: vertical, diagonal e horizontal. Para isso, foram utilizados caminhos feitos de fita pelo chão para que o robô percorresse. As crianças se sentaram todas à frente dos percursos para que o referencial de todas fosse o mesmo, assim elas não confundiriam as orientações vertical e horizontal. No fim, elas tinham que falar qual caminho o robô estava andando e, caso elas errassem, o robô pararia e recomeçaria os caminhos novamente.

\subsection{Sequência}

Neste experimento, os alunos reviram o conceito de sequência numéricas e contagem. Desta vez, ao invés de ser avaliado como eles contavam, foram apresentados vários cartões, cada um com um número, e pedido que eles colocassem os números em ordem crescente e, assim, o robô passaria por cima de cada número completando um percurso. Quando ele chegasse ao fim, os cartões eram embaralhados e pedido novamente que as crianças os alinhassem, só que dessa vez em ordem decrescente, e assim o robô poderia completar o seu caminho. Os alunos já sabiam como escrever cada número por já ser um conceito ensinado dentro da pré-escola. Entretanto, a maneira como elas reagiram aos termos "crescente" e "decrescente" mostrou que era um assunto novo para elas.

\subsection{Dobro e metade}

Os alunos já conheciam operações de soma e subtração, mas ainda não sabiam multiplicar e nem dividir para entender o conceito de dobro e metade. Portanto, ao invés de usar operações, este conceito foi mostrado visualmente por meio das pilhas do robô. Para começar foi mostrado que o robô precisava de 8 pilhas para funcionar, posteriormente foi dito que seria tirado metade das pilhas, e com o restante seria tirado mais metade, até que só sobraria uma pilha, e esta seria tirada. Feito isso, as crianças agora tinham que colocar as pilhas no robô e ir mostrando qual seria o dobro de cada quantidade de pilha colocada. No primeiro momento, foi fácil para eles descobrirem sozinhos o dobro de 1,2 e 4 pois os professores já haviam mostrado qual era a metade de 8,4 e 2 . A maior dificuldade foi quando o robô foi deixado de lado, e um número maior que 10 de pilhas foi colocado á mesa, elas mostraram-se mais confusas e aos poucos ficando entediadas.

\subsection{Paridade}

Após saberem diferenciar metade e dobro, foi ensinado como identificar um número par e um número ímpar. Este experimento foi realizado de duas formas. A primeira foi utilizando pilhas da mesma maneira que foram utilizadas na última aula: eram mostradas quantidades de pilha de número par e depois quantidades ímpares. Depois para testar o conhecimento delas, a atividade proposta foi fazer o robô dar passos de forma que elas pudessem contá-los e responder se a quantidade de passos era um valor par ou ímpar. 
VIII Congresso Brasileiro de Informática na Educação (CBIE 2019)

Anais do XXX Simpósio Brasileiro de Informática na Educação (SBIE 2019)

Algumas crianças conseguiram verificar como a sequência de números pares iam se formando e, no geral, todas sabiam a diferença de par e ímpar sem precisar fazer operação de divisão.

\subsection{Programação}

Nesta aula, um dos professores levou o seu notebook para apresentar às crianças o software LEGAL para ensiná-las a programar. Por serem crianças não alfabetizadas, elas foram instruídas a utilizar o painel com comandos visuais, onde elas apertavam os botões que dariam as "ordens" para o robô. Depois que entenderam o funcionamento do código, elas realizaram um desafio proposto pelos professores,fazendo o robô percorrer um pequeno circuito. Como o uso de computadores não havia acontecido até então, as crianças ficaram empolgadas para realizar o desafio e até discutiram entre si para a resolução do mesmo.

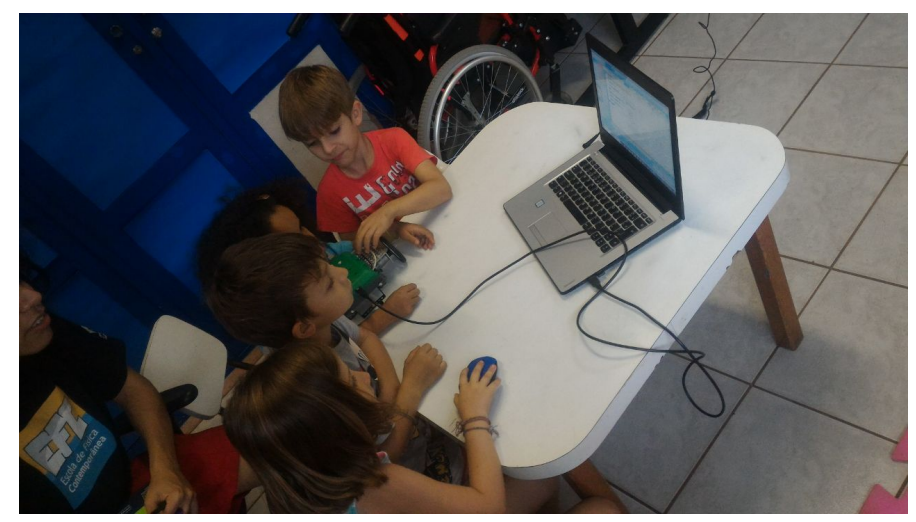

Figura 3. Alunos aprendendo sobre programação

\section{Discussão}

Durante as aulas, algumas anotações eram tomadas para análise posterior. O dado mais fácil de captar foi a relação de perguntas feitas e respostas dadas. Todas as vezes que os alunos respondiam de forma correta ou errada, eram marcadas em uma planilha. Os dados que exigiram maior atenção foram quando e como as crianças interagiam, assim como também foi anotado quando não havia manifestação delas.

Desta forma, foram escolhidos quatro fatores principais para estudo da interação a longo prazo: o chamado "fator novidade", a maneira como os professores deram as aulas, a quantidade de acertos dos alunos e, por último, o engajamento. As notas do fator novidade e da maneira abordada foram dadas de acordo com a atividade e assunto do professor, enquanto que as notas dos dois outros fatores foram dadas para cada aluno individualmente de acordo com o comportamento deles. E estas notas classificavam o interesse deles e uma média foi tirada considerando as respostas corretas e incorretas. Para classificar o "fator novidade" foram dadas três notas padrões: 10 para um assunto que os alunos já conheciam, que foi ensinado em aulas anteriores; 50 para um assunto que eles já haviam visto, mas não tinham entendido; e 100 para um assunto completamente novo. A maneira abordada em cada aula foi classificada pelos próprios professores em uma escala de 0 a 100, na qual 0 representava aula pouco atrativa e 100 aula muito atrativa. Já as notas de acertos foram classificadas como em uma prova, a quantidade de respostas certas 
VIII Congresso Brasileiro de Informática na Educação (CBIE 2019)

Anais do XXX Simpósio Brasileiro de Informática na Educação (SBIE 2019)

foram somadas e divididas pela quantidade total de perguntas. As notas do engajamento foram maiores quando as crianças faziam observações coerentes, quando se empolgavam na atividade ou se mostravam curiosas; as notas medianas foram dadas quando elas dispersavam, falavam de outro assunto, ou ficavam entediadas; e as menores notas foram dadas quando elas não queriam ficar na aula, quando faziam qualquer outra atividade sem ser a da aula, ou também quando não esboçavam reação.

Com essas notas, foram montados dois gráficos, um representando os dados obtidos no primeiro semestre de aula e o segundo obtido no segundo semestre, depois das férias. Essa separação foi feita considerando que os alunos teriam reações diferentes de um semestre para o outro pois, como já esperado, a interação a longo prazo poderia ser falha, de acordo com os estudos [Kanda et al. 2007] [Sung et al. 2009]. De fato, os resultados mostram que os alunos obtiveram uma nota maior de engajamento quando o contato com a robótica era novidade, comparados ao segundo semestre. Pelos gráficos, pode-se observar que os alunos estiveram $11,71 \%$ mais engajados no primeiro semestre do que no segundo.

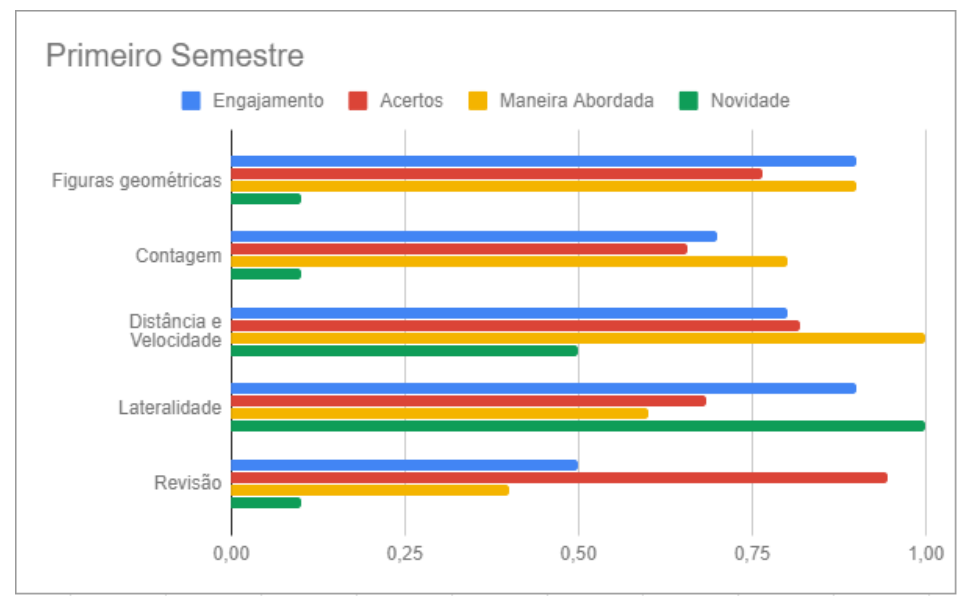

Figura 4. Gráfico 1 - Primeiro Semestre

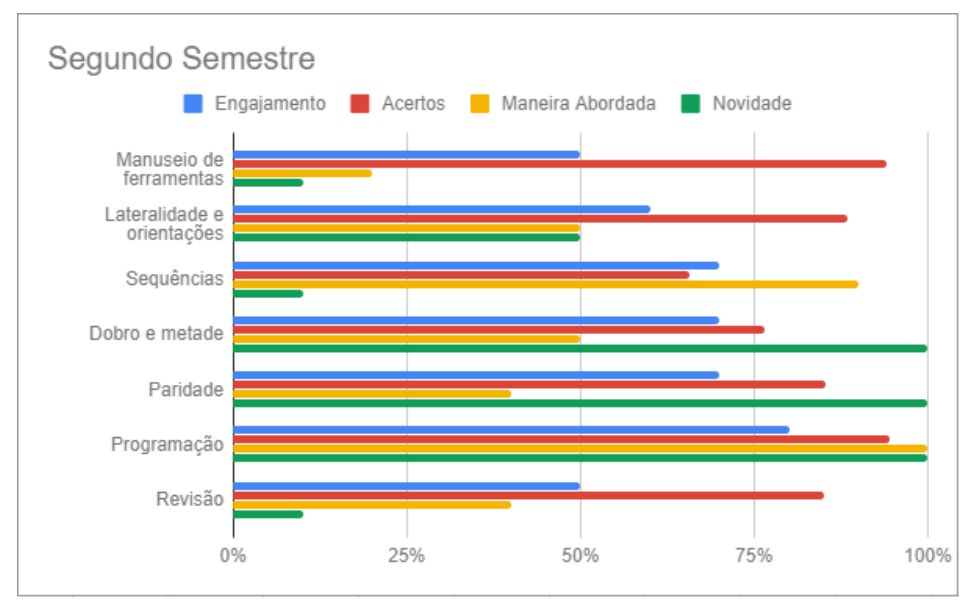

Figura 5. Gráfico 2 - Segundo Semestre

Entretanto, este estudo não foi baseado apenas no engajamento. Percebeu-se pelo primeiro semestre, que as aulas anteriores as dadas neste período tiveram bom aproveita- 
VIII Congresso Brasileiro de Informática na Educação (CBIE 2019)

Anais do XXX Simpósio Brasileiro de Informática na Educação (SBIE 2019)

mento já que houve uma boa quantidade de acertos das perguntas sobre assuntos já vistos antes $(78,046 \%)$. Posteriomente, foi observado um aproveitamento ainda melhor nas respostas do segundo semestre, pois a porcentagem de acertos em assuntos já abordados foi de $83,325 \%$. É possível observar também que dependendo de quão novo e interessante é o assunto abordado, as respostas são melhores, assim como o interesse do aluno, como é observado, por exemplo, na aula de programação ocorrida no segundo semestre. Em compensação, os alunos ficavam facilmente entediados quando se repetiam a atividades nas aulas de revisão.

A principal análise feita foi quando os quatro fatores foram analisados em conjunto, dando atenção maior a maneira abordada pelos professores. Independente se o assunto tratado na aula era novo ou não, caso os professores fizessem uma atividade mais atrativa o engajamento dos alunos aumentava. Ou seja, quando os alunos gostavam da maneira que a matéria era abordada, eles tinham maior abertura para responder as perguntas, e também se mostravam mais interessados no robô e no conteúdo. Para comprovar isso, foi feita a análise das diferentes aulas abordando o mesmo assunto. Na primeira aula de montagem, onde os alunos só tinham que parafusar as mesmas peças do robô, eles se aborreciam ou mesmo não completavam a tarefa. Na segunda, quando eles deveriam fazer uma montagem diferente, acrescentando um suporte a mais do modelo ideal, ou colocar algum enfeite, eles brigavam entre si para realizar a tarefa primeiro. Já nas aulas sobre lateralidade, quando as crianças só podiam assistir ao robô fazendo percursos e dizer para qual lado ele virava, elas respondiam automaticamente, e muitas vezes sem atenção. E quando elas podiam dar os comandos por meio de voz ao robô para que ele andasse; normalmente dizendo frases como "Por favor robô, vire á esquerda. Obrigado."; ou até mesmo andar ao lado dele, elas mostravam mais interesse em participar.

Portanto, o fator que mais interferiu na interação das crianças neste ambiente foi como as aulas foram montadas. Quando as aulas exigiam que as crianças manipulassem mais os robôs, mesmo utilizando o mesmo kit robótico, e se tratando várias vezes do mesmo assunto, elas se engajavam mais. Além disso, o uso contínuo do mesmo robô fez as crianças se sentirem cada vez mais familiarizadas com ele, dando liberdade para elas tomarem iniciativa para responder questões, fazer perguntas e interagir com o robô.

\section{Conclusão}

Neste artigo foi feito um estudo para verificar o comportamento de estudantes de 04 a 06 anos no aprendizado de conceitos de matemática, raciocínio lógico, capacidade de trabalho em grupo e programação, usando um kit robótico. O estudo foi feito durante 01 ano e meio e usando o mesmo kit robótico. Foram investigados dois pontos. O primeiro deles, se os alunos se sairiam melhor quando os conceitos já estavam mais sedimentados ou se eram novidades para eles e o segundo ponto foi para entender quando e por que o aluno perde o interesse das aulas de robótica. Foram analisados quatro fatores considerados importantes, porém subjetivos, para tornar as aulas mais atrativas: forma abordada, sucesso, novidade e engajamento.

A quantidade de acertos dos alunos não classifica necessariamente o quanto eles estão engajados na aula. A atenção deles é mais perceptível quando eles tem mais interação com o robô, em aulas mais elaboradas e criativas que permitem isso, também quando é exigido que eles pensem mais. O nível de dificuldade de um assunto abordado 
VIII Congresso Brasileiro de Informática na Educação (CBIE 2019)

Anais do XXX Simpósio Brasileiro de Informática na Educação (SBIE 2019)

também não influencia o interesse do aluno, visto que em uma aula mais complicada, eles podem tanto perder o foco quanto ficarem instigados.

Ensinar conceitos matemáticos pode ser tornar mais atrativo com o uso de robôs em sala de aula, visto que os alunos aprenderam conceitos de dobro e metade, números pares e ímpares, sem mesmo saber multiplicar e dividir. Mas, ainda é um desafio manter a atenção dos alunos quando essa interação se torna rotineira. A inovação dos exercícios e a maneira que é abordada a interação das crianças com o robô são pontos fundamentais para melhores resultados. Em trabalhos futuros serão estudadas maneiras de fazer o mesmo kit robótico se tornar mais atrativo. Também serão implementadas aulas que permitam maior interação entre o robô e os estudantes, fazendo-os programar o robô por meio de um tablet e monta-lo com formatos mais humanoides e animalescos, criando uma relação diferente entre aluno e robô.

\section{Referências}

Andujar, M., Ekandem, J., Alvarez, I., James, M., and Gilbert, J. (2011). Are educational video games all they're cracked up to be?: A physiological approach for measuring engagement in educational video games vs. conventional learning techniques. In Proceedings of World Conference on E-Learning in Corporate, Government, Healthcare, and Higher Education, pages 539-544.

Ausubel, D. P. (1982). A aprendizagem significativa: a teoria de david ausubel. São Paulo: Moraes.

Chella, M. T. (2005). Ambiente de robótica educacional com Logo.

Kanda, T., Sato, R., Saiwaki, N., and Ishiguro, H. (2007). A two-month field trial in an elementary school for long-term human x2013; robot interaction. IEEE Transactions on Robotics, 23(5):962-971.

Leite, I., Martinho, C., and Paiva, A. (2013). Social robots for long-term interaction: A survey. International Journal of Social Robotics, 5(2):291-308.

Oliveira, R. (2007). Tecnologia na aula de matemática: Robótica na educação. Tese Departamento de Matemática e Engenharia, Universidade de Madeira, Minas Gerais, p.39-45.

Papert, S. M. (1985). Logo: Computadores e educação. São Paulo, Editora, Brasiliense.

Perrenoud, P. (1999). Construir competências é virar as costas aos saberes. Pátio. Revista Pedagógica, 11:15-19.

Sung, J., Christensen, H. I., and Grinter, R. E. (2009). Robots in the wild: Understanding long-term use. In Proceedings of the 4th ACM/IEEE International Conference on Human Robot Interaction, HRI '09, pages 45-52, New York, NY, USA. ACM.

Thomaz, S., Aglaé, A., Fernandes, C., Pitta, R., Azevedo, S., Burlamaqui, A., Silva, A., and Gonçalves, L. M. (2009). Roboeduc: a pedagogical tool to support educational robotics. In 2009 39th IEEE Frontiers in Education Conference, pages 1-6. IEEE.

Vygotsky, L. S. (1993). Pensamento e linguagem. Martins Fontes, São Paulo. 